\title{
LOW-LOSS MICROSTRIP MEMS TECHNOLOGY FOR RF PASSIVE COMPONENTS
}

\author{
L. Martoglio", E. Richalot ${ }^{*}$, O. Picon ${ }^{*}$, G. Lissorgues-Bazin ${ }^{* *}$, C. Vasseure ${ }^{* *}$ \\ *Université Marne-la-Vallée, Bâtiment Lavoisier, rue Galilée, 77420 Champs-sur-Marne - France, \\ 01.60.95.72.79,1martogl@univ-mlv.fr, 01.60.95.72.60, richalot@univ-mlv.fr, 01.60.95.72.84,picon@univ-mlv.fr \\ ** Groupe ESIEE, Cité Descartes, 93162 Noisy-le-Grand - France, \\ 01.45.92.66.96, g.lissorgues@esiee.fr-01.45.92.67.42, c.vasseure@esiee.fr
}

\begin{abstract}
A new low loss and low cost microstrip MEMS technology is presented. Two inverted microstrip lines, one on low loss silicon and the other on glass have been measured and simulated. A good concordance of the results has been obtained. Simulations have been used to study the influence of several parameters, and the results of simulations allow us to adjust the lines dimensions to prescribed characteristics.
\end{abstract}

\section{I- Introduction}

Current microwave and radiofrequency applications require the development of low cost and low loss passive components, which could be easily adapted to silicon fabrication technologies dedicated to planar circuits. Such low loss components, like filters and resonators, are very important to improve the conception of active devices, for example oscillators, mixers, or amplifiers, but also to develop integrated radiofrequency micro-sensors (RF MEMS). Moreover, the technology associated to these new passive components may help reducing interconnection and packaging problems.

Many solutions have already been presented to minimise loss of transmission lines on low resistivity silicon substrates, like microstrip lines on $\mathrm{Si}-\mathrm{SiO}_{2}$ thin film or coplanar wave guides on CMOS silicon [1], [2]. The new microstrip MEMS technology studied in our laboratory looks promising for many reasons : first, the low cost of the substrates, standard silicon and glass, second, the simple technological process, and third the expected good performances.

The microstrip MEMS technology corresponds to inverted microstrip lines on low loss silicon and glass for passive components applications around few GHz, and can be consistent with MMICs technologies.

\section{II- Presentation of the inverted lines}

\section{II-1- Description}

Two kinds of inverted microstrip lines, similar in the fabrication process, have been studied. Anodic bonding is used to define the lines with a controlled air gap of precise thickness g, associating a silicon substrate (resistivity between 4 and $6 \Omega . \mathrm{cm}$ ) and a glass substrate. A first run of wafers has been developed with aluminium metallisations, but further scheduled realisations will be made with gold, to prevent from oxidation. On the first kind of line (figure 1), the ground plane is located on silicon while the transmission line is on glass, whereas the second kind of line (figure 2) shows the opposite geometry. Such structures are interesting in case of heterogeneous micro-machined devices, but also for their lower sensitivity to electromagnetic radiation.

\section{II-2- Experimental results and simulations}

On-wafer measurements have been performed using a vector network analyser HP 8510 between $1 \mathrm{GHz}$ and $8 \mathrm{GHz}$ with pitch probes. Such measurements requiring coplanar access, transitions between coplanar and microstrip geometry have been added to lines 1 and 2. Measurements have been performed for two different lengths ( $5 \mathrm{~mm}$ and $1.5 \mathrm{~mm}$ ) to be able to extract the transition influence.

Experimental results about the lines parameters between 1 and $8 \mathrm{GHz}$, obtained after extraction of the transitions, are compared to HP-Momentum simulations (figures 3, 4). The simulations have been processed with an average value of $5 \Omega . \mathrm{cm}$ for the silicon resistivity. We observe good agreement between simulations and measurements, and we can notice that the attenuation coefficient is lower than in case of classical microstrip lines [3]. As expected, losses for line 1 on glass are much lower than losses for line 2 on silicon. Further more, line 1 on glass presents a quasi-constant characteristic impedance $Z_{c}$ over the whole frequency range (figure 5). 


\section{III- Realisation of passive devices}

The influence of the lines parameters, namely their widths, the air gap high and the silicon properties, has been studied using HP-Momentum simulations. Passive structures can be better designed using these simulations results. For example, by giving the increase of the characteristic impedance with air gap and its decrease both with line width and silicon permittivity, simulations indicate how to obtain a line with a chosen characteristic impedance.

The influence of the line width on characteristic impedance for both lines is shown on figure 6 . The simulated lines have a width of $30 \mu \mathrm{m}$ and the other parameters are those of figure $1 \& 2$.

The following results are related to lines on glass and given at $5 \mathrm{GHz}$ as a function of the ratio $\mathrm{W} / \mathrm{g}$, W being the line width and $g$ the air gap. Characteristic impedances $Z_{c}$ are given on figure 8 and phase shifts per unit length on figure 9. Figures 10 to 12 show the variation of the distributed elements of the classical equivalent transmission line circuit model given on figure 7 [4]. The resistance $\mathrm{R}$ includes the resistance of the metallic line and the serial substrate resistance, the inductance $\mathrm{L}$ represents the magnetic energy stored in the higher-order modes, the conductance $\mathrm{G}$ describes the substrates losses, and the capacitance $\mathrm{C}$ represents the electric energy stored. The values obtained for the conductance $\mathrm{G}$ are very low (between $10^{-3}$ and $5 \cdot 10^{-3} \mathrm{~S} / \mathrm{m}$ ).

The simulation of three cascaded transmission lines has been performed with HP-Momentum, with an air gap g of 18 $\mu \mathrm{m}$, the first and third line's width of $50 \mu \mathrm{m}$ and the second of $80 \mu \mathrm{m}$ (fig. 13). The reflection coefficient obtained is given on figure 14 . This structure is a resonator that could be used as an elementary cell of a filter.

\section{V-Conclusion}

Promising results have been obtained for the two lines presented. Good performances have been obtained whereas the substrates are low cost and the technology process is quite simple. There is a good concordance of the results obtained by measurement and simulation.

The influence of the line parameters on their characteristics has been studied. This study helps us to better know the behaviour of these lines, and makes possible to adjust the line dimensions to the desired characteristics. The synthesis of passive elements like filters and resonators is now possible.

\section{References:}

[1] H. Hasegawa, M. Furukawa, H. Yanai, "Properties of microstrip line on $\mathrm{Si}_{-} \mathrm{SiO}_{2}$ system", IEEE Trans. MTT, Vol. 19, N 11, pp. 869-881, 1971.

[2] V. Milanovic, M. Ozgur, D.C. DeGroot, M. Gaitan, M. E. Zaghloul, "Characterization of Braod-Band Transmission for coplanar Waveguides on CMOS Silicon substrates", IEEE Trans. MTT, Vol. 46, N 5, pp. 632 - 640, 1998.

[3] G.E. Ponchak, "RF transmission lines on silicon substrates", $29^{\text {th }}$ EuMC, Munich, pp. 158-161, 1999.

[4] F. Gardiol, « Microstrip circuits », Wiley-Interscience, 1994. 


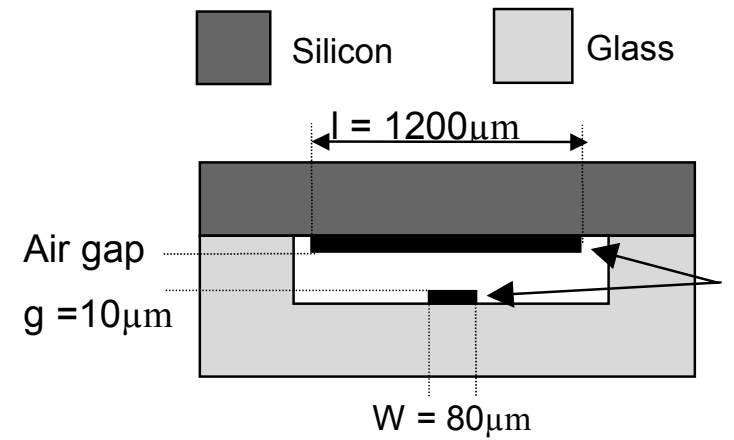

Figure 1 : Line 1 on glass

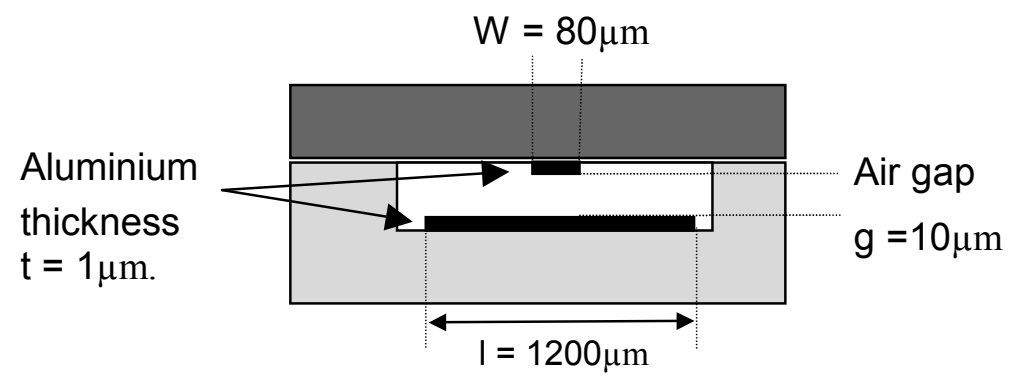

Figure 2 : Line 2 on silicon

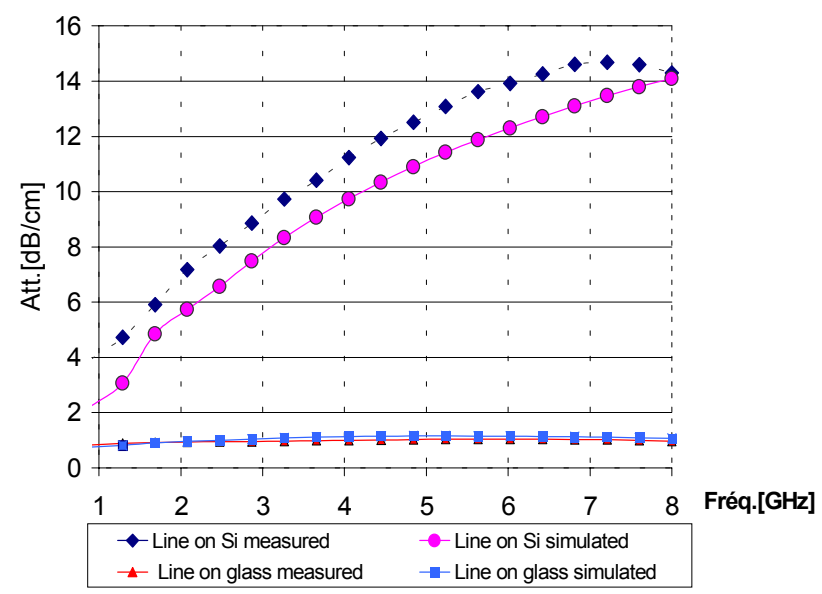

Figure 4 : Attenuation per unit length .

Figure 3 : Phase-shift per unit length.

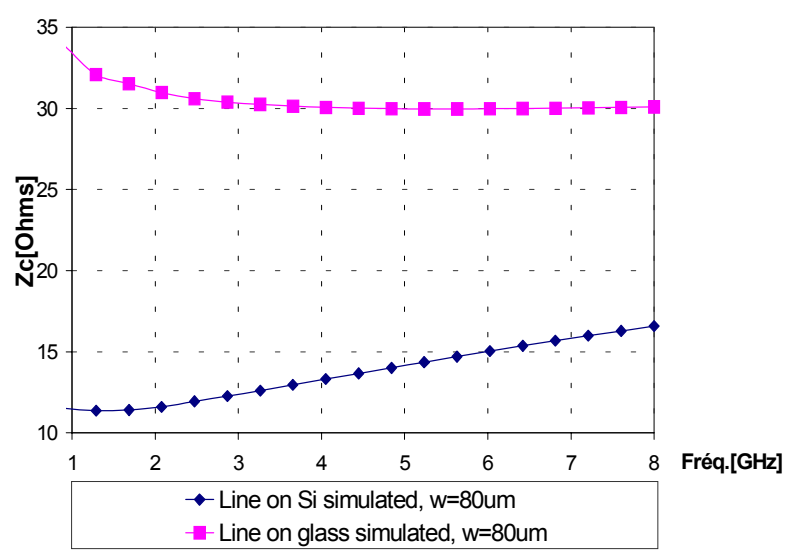

Figure 5 : Characteristic impedance for $\mathrm{W}=80 \mu \mathrm{m}$

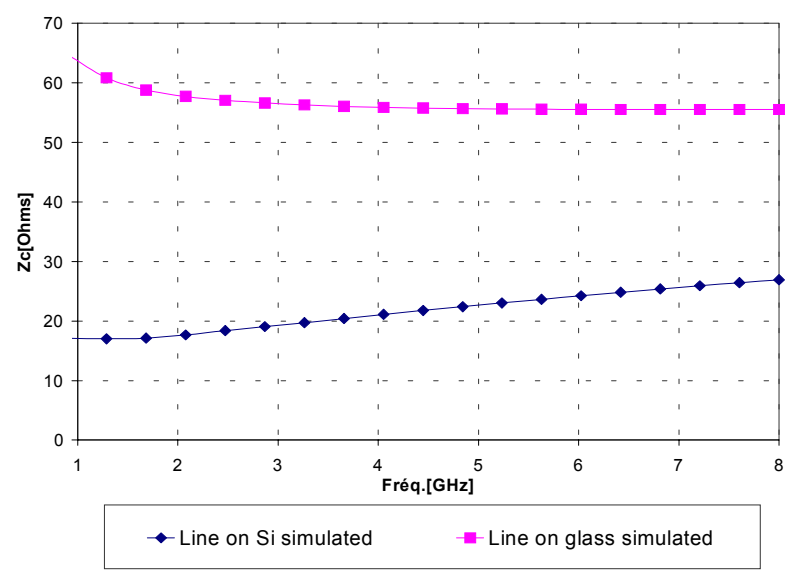

Figure 6 : Characteristic impedance for $W=30 \mu \mathrm{m}$

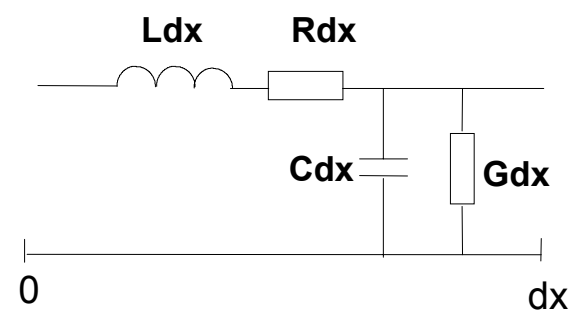

Figure 7 : Elementary cell model for the transmission line 


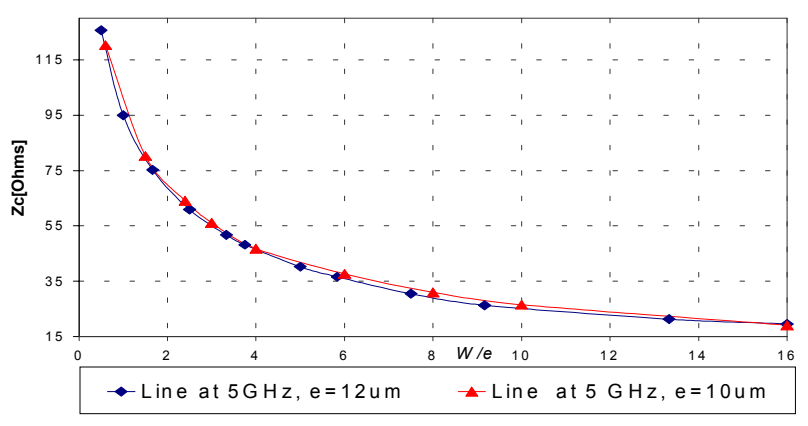

Figure 8 : Characteristic impedance

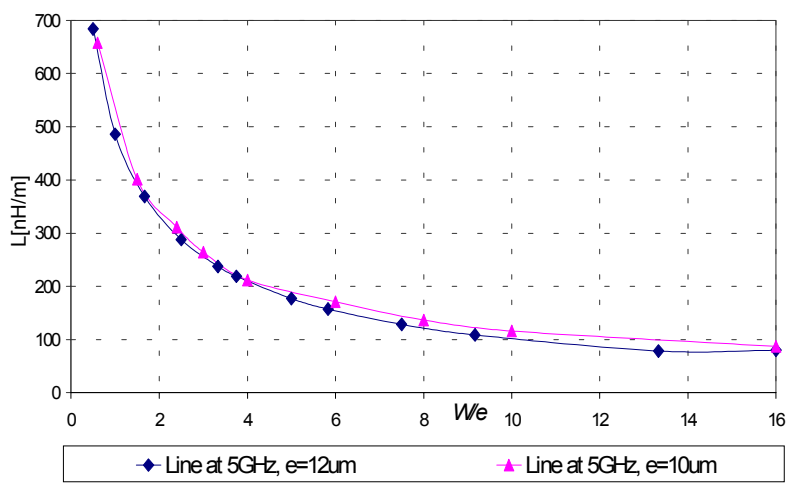

Figure 10 : Inductance per unit length.

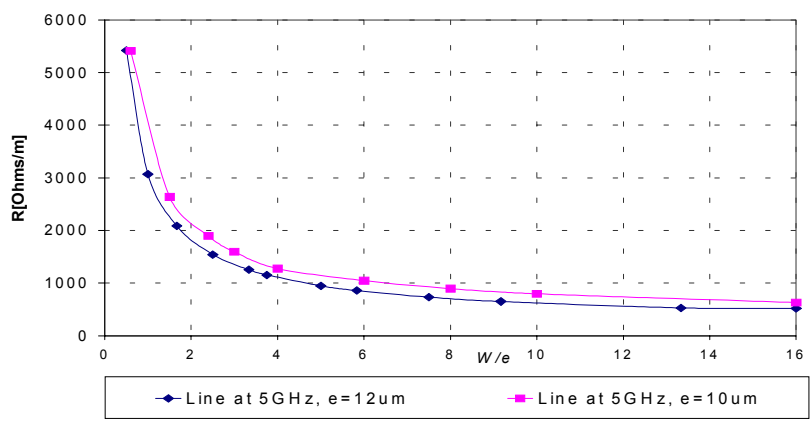

Figure 12 : Resistance per unit length.

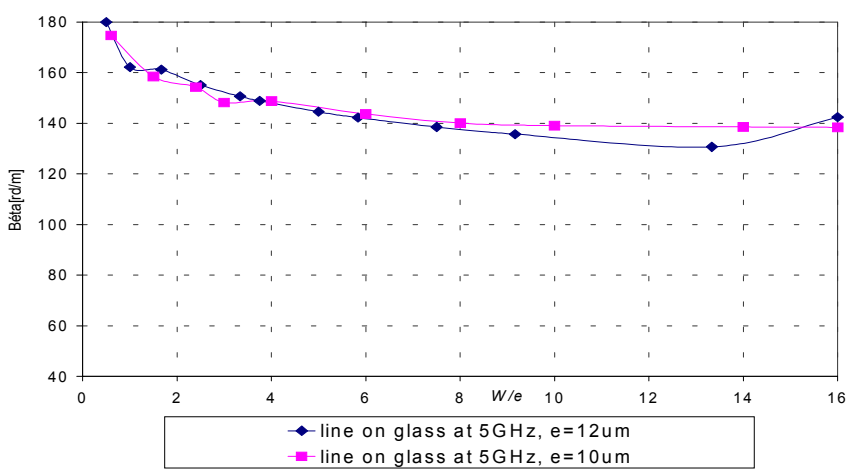

Figure 9 : Phase shift per unit length

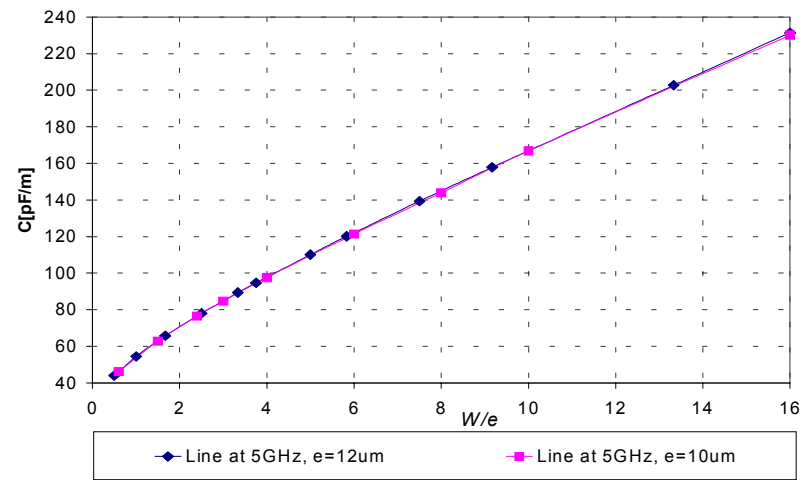

Figure 11 : Capacitance per unit length

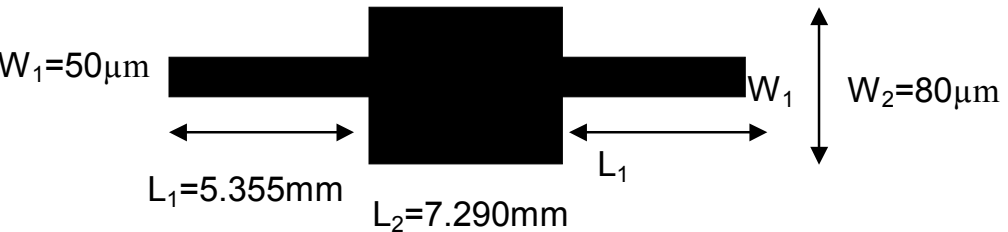

Figure 13 : Cascaded transmission lines

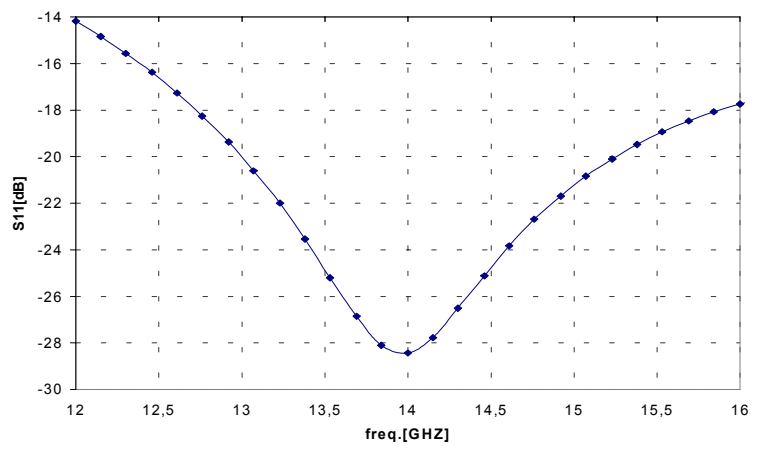

Figure 14 : Reflection coefficient of the cascaded lines 